\title{
Effect of postprandial lipaemia and Taq $1 B$ polymorphism of the cholesteryl ester transfer protein (CETP) gene on CETP mass, activity, associated lipoproteins and plasma lipids
}

\author{
Enda Noone*, Helen M. Roche, Irene Black, Anne-Marie Tully and Michael J. Gibney \\ Unit of Nutrition, The Trinity Centre for Health Sciences, St James's Hospital, James's St, Dublin 8, \\ Republic of Ireland
}

(Received 14 July 1999 - Revised 2 December 1999 - Accepted 13 December 1999)

\begin{abstract}
A large number of studies in recent years have investigated the effects of hyperlipidaemias and diabetes on cholesteryl ester transfer protein (CETP) on neutral lipid transfer activity and plasma lipids. There has been an ongoing debate as to whether CETP is pro- or anti-atherogenic as it provides a mechanism for the transfer of cholesterol from the cardioprotective HDL subfraction to the potentially atherogenic LDL subfraction. This study was designed to investigate whether there was significant variability of CETP mass and activity in a large normolipidaemic population and whether there is an association between CETP and plasma lipoprotein composition. The presence of a known polymorphism of CETP gene (Taq 1B) was investigated to see if there was any association between this polymorphism and CETP mass and activity, and plasma lipids. There was significant $(P<0 \cdot 0001)$ increase in CETP mass and activity in plasma postprandially at $6 \mathrm{~h}$. Using multiple stepwise regression analysis there was significant association with fasting CETP mass and activity $(\beta=0.055 ; P=0.002)$ and triacylglycerol-rich lipoprotein $(\beta=0.013$; $P=0.005)$ and postprandial CETP mass $(\beta=0.254 ; P=0.007)$. Repeated-measures analysis showed a strong association between the absence of Taq 1B polymorphism and low CETP mass and elevated HDL- and $\mathrm{HDL}_{2}$-cholesterol and HDL-phospholipid concentrations than did those who were homozygous or heterozygous for the presence of the restriction site.
\end{abstract}

Cholesteryl ester transfer protein: Taq 1B polymorphism: Postprandial lipaemia

Increases in cholesteryl ester transfer protein (CETP) activity during postprandial lipaemia have been reported previously (Tall et al. 1986) where a 2-3-fold increase in cholesteryl ester transfer was reported. As a consequence of CETP activity, there is a transfer of cholesteryl ester from HDL particles to VLDL and LDL particles with a reciprocal transfer of triacylglycerol (TAG). Alterations in HDL size and composition occur as a result of CETP activity. Precursors to HDL are pre beta HDL, which contain apolipoprotein (Apo) A1 proteins with a small amount of phospholipid. These pre beta HDL can bind to cells promoting efflux of cellular cholesterol (Fielding \& Fielding, 1995). They may combine with chylomicron remnants produced during postprandial lipaemia and accumulate cholesteryl ester and phospholipids. This results in the formation of mature HDL, which is facilitated through the actions of lecithin-cholesterol acyl transferase (Skinner, 1994). Mature HDL can be divided into $\mathrm{HDL}_{2}$ and $\mathrm{HDL}_{3}$ based on their lipid and lipoprotein composition. HDL subfractions are dynamic and constantly change from more dense $\mathrm{HDL}_{3}$ to less dense $\mathrm{HDL}_{2}$ particularly during postprandial lipaemia through the activities of CETP. TAGrich $\mathrm{HDL}_{2}$ is catabolised by hepatic lipase resulting in the formation of $\mathrm{HDL}_{3}$. VLDL and intermediate-density lipoprotein accept cholesteryl ester from HDL with a reciprocal exchange of TAG into HDL as a result of CETP activity. VLDL and intermediate-density lipoprotein are catabolised to form LDL. A number of publications suggest that CETP activity may be pro-atherogenic because it results in the reduction of HDL-cholesterol, increased production of dense atherogenic LDL and increased catabolism of TAGrich HDL by hepatic lipase (Tall, 1993; Lagrost et al. 1994). The increase in CETP mass, activity and the redistribution of cholesteryl ester from HDL to VLDL and LDL lipoprotein fractions during postprandial lipaemia suggests the pro-atherogenic effect of CETP may be elevated during lipaemia. Cholesterol intake (Quinet, 1990; Fielding \& Fielding 1995), dietary trans fatty acid consumption (Abbey \& Nestel, 1994), alcohol consumption (Savolainen et al. 1990), and genetic variations all account for differences 
in CETP mass and activities in normolipidaemics. Where there are genetic variants of CETP, for example the absence of Taq 1B polymorphism (Bernard et al. 1998), or splicing defects which are common in the Japanese population (Inazo et al. 1990; Koizumi et al. 1991), there are increased HDL-cholesterol concentrations.

A number of previous studies have investigated the effect and frequency of the Taq 1B polymorphism of the CETP gene (Freeman et al. 1993; Hannuksula et al. 1994; Kuivenhoven et al. 1997; Kuivenhoven et al. 1998). Kuivenhoven et al. (1998) noted that the frequency of Taq $1 \mathrm{~B}$ polymorphism in a group of patients with coronary atherosclerosis was $\mathrm{B}+\mathrm{B}+, 35 \%, \mathrm{~B}+\mathrm{B}-, 49 \%$ and $\mathrm{B}-\mathrm{B}-$, $16 \%$. Data from many of these previous studies indicate those who show the absence of the Taq 1B cutting site (B- B-) have lower CETP mass and higher HDL-cholesterol concentrations (Kondo et al. 1989; Freeman et al. 1990). It is hypothesised that an altered HDL-cholesterol concentration in these individuals is a direct result of the presence or absence of the Taq $1 \mathrm{~B}$ polymorphism on the CETP gene. However, a mechanism as to how this occurs is not forthcoming.

The present investigation was designed to address whether there is an increase in CETP mass and activity in response to a test meal containing a typical amount of fat $(40 \mathrm{~g})$ in a large normolipidaemic study group. Although the effects of acute fat ingestion on CETP mass and activity have been previously studied, the majority have measured either CETP mass or activity but not both. Many of the previous studies on CETP have concentrated on CETP mass and activity in hyperlipidaemic subjects in order to ascertain if their condition results in altered CETP. In this present study, a large number of lipid variables were analysed to try and ascertain if CETP activities could be attributed to greater coronary risk factors in a normolipidaemic population. Finally an investigation into the effects of the Taq 1B polymorphism on CETP mass or activity and associated lipids in fasting and postprandial states was carried out.

\section{Methods \\ Study subjects}

The study was conducted in the nutrition laboratory at the Trinity Centre, St James's Hospital, Dublin, Republic of Ireland. Sixty-three non-smoking healthy subjects were recruited from the personnel of Trinity College Dublin and St James's Hospital, Dublin. Biochemical exclusion criteria included fasting plasma cholesterol $<7.0 \mathrm{mmol} / 1$, plasma TAG $<2.0 \mathrm{mmol} / \mathrm{l}$, plasma glucose $<110 \mathrm{mg} / \mathrm{dl}$, plasma $\gamma$-glutamyltransferase $<60 \mathrm{IU} / \mathrm{l}$, haemoglobin $>12 \mathrm{~g} / \mathrm{dl}$ and a BMI $<30$. Each study day began between 07.30 and 08.00 hours, following a $12 \mathrm{~h}$ overnight fast. Subjects were asked to abstain from alcohol and exercise $24 \mathrm{~h}$ before a postprandial day. During postprandial investigation each subject was asked to abstain from food and drink with the exception of water, decaffeinated coffee and diet drinks. The test meal was prepared each day. Each subject received $40 \mathrm{~g}$ fat which was high in monounsaturated fatty acids (Flora Sunflower Oil, Van Den Bergs Ltd, Crawley, Sussex, $\mathrm{UK}), 150 \mathrm{~g}$ skimmed milk and $5 \mathrm{~g}$ orange-flavoured Modjul system (Scientific Hospital Supplies International, Liverpool, UK) which was mixed with water.

A 21 gauge $32 \mathrm{~mm}$ venous catheter (Abbott Ireland Ltd, Dublin, Republic of Ireland) was inserted into the antecubital vein of the non-dominant forearm. Blood samples for CETP analysis were collected in $5 \mathrm{ml}$ citrated tubes (0.106 M-sodium citrate) (Starstead monovette). Blood samples for lipid analysis were collected into $10 \mathrm{ml}$ heparinised vacutainers. All blood samples were drawn before the test meal was administered. The test meal was consumed within $15 \mathrm{~min}$. A further blood sample was drawn $6 \mathrm{~h}$ after the test meal. All samples were centrifuged (3000 r.p.m. for $15 \mathrm{~min}$ ) at room temperature. Plasma was removed, mixed, and aliquots of $0.5 \mathrm{ml}$ fractions were made. Samples for CETP analysis were snap-frozen under liquid $\mathrm{N}_{2}$ and stored $\left(-70^{\circ} \mathrm{C}\right)$ until CETP mass and activity was assayed. Plasma for lipid analysis was stored at $-20^{\circ} \mathrm{C}$.

\section{Laboratory methods}

Analysis of plasma TAG (TAG PAP Biomerieux, Etoile, France), cholesterol (Biomerieux PAP), non-esterified fatty acids (Acyl Co A synthetase-acyl Co A oxidase, Wako Chemicals Gmbh, Neuss, Germany), phospholipid (Biomerieux PAP), ApoA1 (Biomerieux) were carried out. HDL-cholesterol, TAG, phospholipid and ApoA1 were measured using the methods mentioned previously following precipitation of HDL with Immuno Quantolip HDL (Immuno AG, Vienna, Austria) precipitating reagent. All determinations were performed on a Technicon RA-XT Chemistry Analyser (Technicon Inc., Tarrytown, NY, USA)

CETP activity in plasma was determined using a fluorescent transfer method (WAK-Chemi Medical, Bad Soden, Germany). A fluorescent-labelled cholesterol linoleate is sequestered within a donor particle in a quenched state. CETP facilitates the transfer of cholesteryl ester to an acceptor particle where the fluorescence is unquenched. The increase in fluorescence is proportional to the rate of transfer activity. Total CETP mass in plasma was determined using an alkaline phosphatase-based sandwich ELISA assay as described previously by Clarke et al. (1995).

\section{DNA analysis}

Genomic DNA was isolated from whole blood by haemolysing the red blood cells. White blood cells were pelleted and washed with Tris EDTA (pH 7.5) until no trace of red blood cells was evident. The white blood cells were treated with proteinase $\mathrm{K}$ for $45 \mathrm{~min}$, after which it was denatured. Amplification of a 213 base pair fragment of the CETP gene containing the Taq 1B was carried out using polymerase chain reaction. The forward (GGT CCT AGC TGC ATT GCA AAC) and reverse (GAT GGA GCC TCC GTC GTC ACC TGA) primers were synthesised on a 391 DNA synthesiser (Applied Biosystems, Perkin Elmer Corp., Foster City, CA, USA). The polymerase chain reaction consisted of a 7 min denaturation at $94^{\circ} \mathrm{C}$, then 35 cycles of $94^{\circ} \mathrm{C}$ for $1 \mathrm{~min}, 55^{\circ} \mathrm{C}$ for $1 \mathrm{~min}$ and $72^{\circ} \mathrm{C}$ for $1 \mathrm{~min} 12 \mathrm{~s}$ and finally a $5 \mathrm{~min}$ extension at $72^{\circ} \mathrm{C}$. This polymerase chain reaction programme was carried out on $25 \mu$ reactions containing 
1.25 mM-dATP, -dCTP, -dGTP, -dTTP, $6 \% 20 \mathrm{mM}-\mathrm{Mg}^{2+}$ buffer, 0.6 units and $1 \mu \mathrm{DNA}$ in $15 \mathrm{mM}-\mathrm{Mg}^{2+}$ buffer, plus the forward and reverse primers. The polymerase chain reaction product $(5 \mu \mathrm{l})$ was digested with 1 Unit Taq 1B (Boehringer Mannheim, Mannheim, Germany) for $4 \mathrm{~h}$ at $65^{\circ} \mathrm{C}$. Digestion products were run on $3 \%$ agarose gel. Subjects who did not have restriction site had a band at 213 base pairs (B-B-), heterozygotes had bands at 213, 142 and 71 base pairs (B+B-), while subjects who cut had bands at 142 and 71 base pairs $(B+B+)$.

\section{Data analysis}

All statistical analysis was carried out on an Apple Macintosh statistical package, Data Desk 4.1 (Data Description Inc., New York, NY, USA. The distribution of the data for each variable was assessed. Some of the variables were transformed to normalise the distribution of some of the data sets ( $\sqrt{H D L}, \log$ of CETP data). Paired Student's $t$ test was used to analyse the difference in variables between fasting and $6 \mathrm{~h}$ postprandial samples. Pearson product moment correlation analysis was used to investigate the relationship between plasma lipid and lipoprotein concentrations and CETP metabolism. Stepwise multiple regression analysis was used to investigate the factors which determined CETP mass and activity in the fasted and $6 \mathrm{~h}$ postprandial state. One-way ANOVA was used to compare significant difference in CETP mass, activity and plasma lipids according to Taq 1B polymorphism grouping.

\section{Results}

Sixty-three subjects, thirty-nine males and twenty-four females, participated in this study. The total study group had a mean age of 32.4 (SD 9.6) years, a mean weight of 73.48 (SD 13.65) kg and a mean BMI of 24.14 (SD 2.62) $\mathrm{kg} / \mathrm{m}^{2}$. The effect of postprandial lipaemia on CETP was investigated at two hourly intervals over $8 \mathrm{~h}$. Maximal CETP mass and activity occurred at $6 \mathrm{~h}, 2 \mathrm{~h}$ after peak TAG production. Therefore, the $6 \mathrm{~h}$ time point was used to access the effect of lipaemia on CETP in this investigation. Fasting and $6 \mathrm{~h}$ postprandial CETP mass, activity and lipid concentrations are given in Table 1. There was a significant increase in CETP mass $(P=0.0014)$ and activity $(P \leq$ 0.0001 ) from the fasted state to $6 \mathrm{~h}$ after ingestion of test meal. Plasma TAG and plasma non-esterified fatty acids were significantly increased $(P \leq 0.0001)$ during postprandial lipaemia at $6 \mathrm{~h}$, while plasma LDL concentrations were significantly $(P=0.01)$ reduced. The compositions of the HDL subfractions are given in Table 2. Total phospholipid, ApoA1 and TAG concentrations were significantly increased $(P \leq 0 \cdot 0001)$ at $6 \mathrm{~h}$. Total HDL-cholesterol did not increase significantly. Plasma concentrations of $\mathrm{HDL}_{3}-\mathrm{ApoA} 1$ and -TAG were significantly $(P<0.05)$ increased $6 \mathrm{~h}$ postprandially, whilst cholesterol and phospholipid concentrations were not altered significantly. All of the lipids of the $\mathrm{HDL}_{2}$ subfraction increased significantly $6 \mathrm{~h}$ after ingestion of test meal, with the increase in $\mathrm{HDL}_{2}$-TAG being the most significant $(P \leq 0 \cdot 0001)$. There was a strong positive relationship between CETP mass and activity in the fasted and postprandial states for the total study group $(r 0 \cdot 470, P \leq 0 \cdot 0001)$.

\section{Plasma lipids and cholesteryl ester transfer protein metabolism}

Fasting CETP mass was significantly correlated with age ( $r$ 0.310, $P=0 \cdot 012$ ). Postprandial CETP mass $(6 \mathrm{~h})$ was significantly correlated with BMI $(r 0.270, P=0.032)$ and body weight ( $r 0.265, P=0.035)$. Postprandial CETP activity was not significantly associated with age, weight and BMI. Stepwise multiple regression analysis of fasting CETP mass demonstrated that fasting plasma cholesterol was the most important factor $(\beta=0.354 ; P=0.0003)$, followed by age $(\beta=0.0233 ; P=0.012)$. Stepwise multiple regression analysis of CETP mass at $6 \mathrm{~h}$ showed that fasting CETP mass was the most important determinant $(\beta=0.0192 ; P=$ 0.0001 ), followed by fasting LDL-cholesterol concentration ( $\beta=0.047 ; \quad P=0.0031), \mathrm{HDL}_{3}$-TAG concentration $(\beta=$ $0.898 ; P=0.0101)$ and $\mathrm{HDL}_{3}$-ApoA1 concentration $(\beta=$ $-0 \cdot 240 ; P=0 \cdot 015)$. Multiple stepwise regression analysis of fasting CETP activity showed that fasting CETP mass was the principle determinant $(\beta=26 \cdot 746 ; P=0.0001)$, while fasting plasma non-esterified fatty acids had a small effect $(\beta=43.002 ; P=0.06)$. Stepwise multiple regression analysis

Table 1. Plasma cholesteryl ester transfer protein mass and activity and plasma lipids in the fasted state and at $6 \mathrm{~h}$ following an acute fat load in healthy normolipidaemic subjects*

(Mean values and standard deviations for sixty-three subjects)

\begin{tabular}{|c|c|c|c|c|}
\hline & \multicolumn{4}{|c|}{ Time } \\
\hline & \multicolumn{2}{|c|}{0 hours } & \multicolumn{2}{|c|}{6 hours } \\
\hline & Mean & SD & Mean & SD \\
\hline CETP mass $(\mu \mathrm{g} / \mathrm{ml})$ & $2 \cdot 040$ & 0.686 & $2 \cdot 314 \dagger$ & 0.985 \\
\hline CETP activity (pmol/NBD-CE transfer/3h) & $29 \cdot 851$ & $7 \cdot 232$ & $39.011 \dagger \dagger$ & $12 \cdot 45$ \\
\hline Plasma triacylglycerol $(\mathrm{mmol} / \mathrm{l})$ & 0.987 & 0.467 & $1.071 \dagger \dagger$ & 0.477 \\
\hline Plasma NEFA (mmol/l) & 0.482 & 0.185 & $0.616 \dagger$ & 0.199 \\
\hline Plasma cholesterol (mmol/l) & 4.982 & 1.048 & $4.926 \dagger$ & 0.989 \\
\hline Plasma LDL-cholesterol (mmol/l) & 3.621 & 0.785 & $3.582 \dagger$ & 0.653 \\
\hline
\end{tabular}


Table 2. Concentrations of cholesterol, phospholipid and triacylglycerol (TAG) in the high-density lipoprotein (HDL) subfractions in the fasted and postprandial states following an acute fat load in healthy normolipidaemic subjects*

(Mean values and standard deviations for sixty-three subjects)

\begin{tabular}{|c|c|c|c|c|c|c|c|c|c|c|c|c|}
\hline & \multicolumn{4}{|c|}{ Total HDL } & \multicolumn{4}{|c|}{$\mathrm{HDL}_{3}$} & \multicolumn{4}{|c|}{$\mathrm{HDL}_{2}$} \\
\hline & \multicolumn{2}{|c|}{$\mathrm{Oh}$} & \multicolumn{2}{|c|}{$6 \mathrm{~h}$} & \multicolumn{2}{|c|}{$\mathrm{Oh}$} & \multicolumn{2}{|c|}{$6 \mathrm{~h}$} & \multicolumn{2}{|c|}{$\mathrm{Oh}$} & \multicolumn{2}{|c|}{$6 \mathrm{~h}$} \\
\hline & Mean & SD & Mean & SD & Mean & SD & Mean & SD & Mean & SD & Mean & SD \\
\hline Cholesterol $(\mathrm{mmol} / \mathrm{l})$ & $1 \cdot 162$ & 0.310 & $1 \cdot 174$ & 0.358 & 0.917 & 0.254 & 0.887 & 0.285 & 0.248 & 0.221 & $0.332 † \dagger$ & 0.254 \\
\hline Phospholipid (mmol/l) & 1.047 & 0.230 & $1 \cdot 168 \dagger+\dagger$ & 0.296 & 0.856 & 0.205 & 0.875 & 0.278 & 0.213 & 0.174 & $0.335 \dagger \dagger$ & 0.279 \\
\hline ApoA1 (mmol/l) & 0.582 & 0.223 & $0.726+\dagger \dagger$ & 0.106 & 0.494 & 0.212 & $0.570 \dagger$ & 0.176 & 0.126 & 0.119 & $0.187 \dagger$ & 0.171 \\
\hline TAG $(\mathrm{mmol} / \mathrm{l})$ & 0.053 & 0.019 & $0.070 \dagger \dagger \dagger$ & 0.03 & 0.045 & 0.017 & $0.055 \dagger$ & 0.027 & 0.011 & 0.011 & $0.021 \dagger \dagger \dagger$ & 0.019 \\
\hline
\end{tabular}

Apo, apolipoprotein.

* For details of procedures see pp. 204-205.

Mean values were significantly different from those at $0 \mathrm{~h}: \dagger P<0.05, \uparrow \dagger P<0.005, \dagger \dagger \uparrow P \leq 0.0001$.

Table 3. Fasting levels of plasma cholesteryl ester transfer protein (CETP) mass, activity, total high-density lipoprotein (HDL) and HDL ${ }_{2}^{-}$ cholesterol and HDL-phospholipid concentrations according to CETP Taq $1 \mathrm{~B}$ genotype in healthy normolipidaemic subjects*

(Mean values and standard deviations for sixty-three subjects)

\begin{tabular}{|c|c|c|c|c|c|c|c|}
\hline & \multicolumn{6}{|c|}{ Genotype } & \multirow{3}{*}{$\begin{array}{c}\text { Statistical significance } \\
\text { of difference } \\
\text { between means } \\
\text { (one-way ANOVA): } P\end{array}$} \\
\hline & \multicolumn{2}{|c|}{$\mathrm{B}-\mathrm{B}-(n 6)$} & \multicolumn{2}{|c|}{$\mathrm{B}-\mathrm{B}+(n$ 34) } & \multicolumn{2}{|c|}{$\mathrm{B}+\mathrm{B}+(n 23)$} & \\
\hline & Mean & SD & Mean & SD & Mean & SD & \\
\hline CETP mass $(\mu \mathrm{g} / \mathrm{ml})$ & 1.342 & 0.773 & $2 \cdot 119$ & 0.623 & $2 \cdot 105$ & 0.674 & 0.002 \\
\hline CETP activity (pmol/NBD-CE transfer/min) & $26 \cdot 116$ & $7 \cdot 229$ & $29 \cdot 72$ & $10 \cdot 130$ & 31.042 & 9.075 & NS \\
\hline HDL-cholesterol $(\mathrm{mmol} / \mathrm{l})$ & 1.506 & 0.598 & 1.114 & 0.237 & 1.140 & 0.292 & 0.017 \\
\hline $\mathrm{HDL}_{2}$-cholesterol $(\mathrm{mmol} / \mathrm{l})$ & 0.526 & 0.405 & 0.200 & 0.173 & 0.245 & 0.173 & 0.05 \\
\hline HDL-phospholipid (mmol/l) & 1.321 & 0.290 & 1.011 & 0.212 & 1.027 & 0.197 & 0.002 \\
\hline
\end{tabular}

NBD-CE, nitrobenzoxadiol-fluorophore-cholesteryl ester.

${ }^{*}$ For details of procedures see pp. 204-205.

of $6 \mathrm{~h}$ CETP activity showed that fasting cholesterol was the principle determinant $(\beta=0.055 ; P=0.0025)$ followed by TAG-rich lipoprotein $(\beta=-0.013 ; P=0.005)$, and mass at $6 \mathrm{~h}(\beta=0.254 ; P=0 \cdot 0070)$.

\section{Taq $1 B$ genotype}

The distribution of CETP Taq 1B alleles within this study group was: $\mathrm{B}+\mathrm{B}+36.5 \%, \mathrm{~B}+\mathrm{B}-53.9 \%$, $\mathrm{B}-\mathrm{B}-9.52 \%$. ANOVA was used on the comparison of the lipid concentrations of the $\mathrm{B}+\mathrm{B}+, \mathrm{B}+\mathrm{B}-$ and $\mathrm{B}-\mathrm{B}-$ polymorphisms to see if Taq $1 \mathrm{~B}$ restriction site exhibited any influence on the lipid profile of subjects grouped according to particular polymorphism; results are shown in Table 3. Those individuals which are homozygous for the absence of the Taq 1B polymorphism $(\mathrm{B}-\mathrm{B}-)$ had a significantly $(P<0.05)$ lower fasting CETP mass, higher fasting $\mathrm{HDL}, \mathrm{HDL}_{2}$-cholesterol and HDL-phospholipid concentration than did those individuals who were heterozygous $(\mathrm{B}+\mathrm{B}-)$ or homozygous $(\mathrm{B}+\mathrm{B}+)$ for the presence of Taq 1B polymorphism (see Table 3). A similar trend was noted when $6 \mathrm{~h}$ CETP and $6 \mathrm{~h}$ plasma lipids were compared according to polymorphism grouping; however, significant statistical association was not achieved.

\section{Discussion}

In a study by Tall et al. (1986) there was a $1 \cdot 1-1 \cdot 7$-fold increase in cholesteryl ester transfer in response to a $135 \mathrm{~g}$ fat-rich test meal. In the present study there was an increase of $1 \cdot 3$-fold in CETP activity $(P=0.0001)$, and $1 \cdot 13$-fold increase in CETP mass $(P=0.0001)$ during postprandial lipaemia in response to a $40 \mathrm{~g}$ fat test meal. Investigation of the rate of production of CETP postprandially in eighteen subjects in the fasted state and at two hourly intervals for $8 \mathrm{~h}$ demonstrated that maximal CETP mass and activity were found at $6 \mathrm{~h}$ after ingestion of test meal, similar to the findings of Tall et al. (1986). The $6 \mathrm{~h}$ samples were used as the time point for CETP and lipid analysis to see the effect of maximal CETP production on plasma lipids after ingestion of the test meal. Castro \& Fielding (1985) demonstrated that cholesteryl ester transfer doubled during postprandial lipaemia. Previous studies show that increases in CETP mass during postprandial lipaemia in type 2 diabetics and normal control subjects were significant (Lottenberg et al. 1996b). Discrepancies as to increases in CETP activity between studies may be explained by fat composition. A test meal rich in monounsaturated fatty acids (which was administered in this present study) tends to produce a lower postprandial response than does a saturated fat meal (Groener et al. 1991; de Bruin et al. 1993) as would the lower dose of fat administered in the test meal. Lottenberg et al. (1996a) demonstrated that increases in CETP activity were also accounted for by increases in substrate availability during lipaemia.

In the present study analysis of HDL subfractions showed the $\mathrm{HDL}_{2}$ subfraction had the greatest increase in lipid 
composition $6 \mathrm{~h}$ postprandially, with $\mathrm{HDL}_{2}$-TAG showing the most significant increase (Patsch et al. 1984, 1987), followed by $\mathrm{HDL}_{2}$-cholesterol, -phospholipid and -ApoA1 concentrations. Total HDL-cholesterol did not change significantly $6 \mathrm{~h}$ postprandially in this study as was demonstrated previously by Karpe et al. (1993). The $\mathrm{HDL}_{3}$ subfraction showed the lowest change in composition during postprandial lipaemia, with significant $(P<0.05)$ increases in $\mathrm{HDL}_{3}$-TAG and -ApoA1.

The finding of the present study that fasting plasma cholesterol is the most important determinant of fasting CETP mass is supported by the study of Kahri et al. (1994) and Tato et al. (1995). In other studies, this association failed to attain statistical significance (Jones et al. 1996; Tato et al. 1997). Tato et al. (1995) also observed associations between postprandial CETP mass and both BMI and weight, but they failed to reach statistical significance. The present study did find these associations to be statistically significant, possibly because of a normolipidaemic study group used in this investigation compared with the study of Tato et al. (1995) where the study group was hypercholesterolaemic.

Multiple stepwise regression analysis demonstrated that fasting plasma cholesterol was the primary determinant of CETP mass followed closely by age which confirms a link between CETP, plasma cholesterol and age, suggesting that plasma cholesterol may determine CETP mass. These data suggest that high CETP levels may be a consequence of elevated plasma cholesterol levels (Bagdade et al. 1992; Inazu et al. 1992). Multiple stepwise regression analysis showed that the predictors of $6 \mathrm{~h}$ postprandial CETP mass were LDL-cholesterol $(\beta=0 \cdot 047), \mathrm{HDL}_{3}$-TAG $(\beta=0.898$; $P=0.01)$ both of which are functional indicators of CETP activity and $\mathrm{HDL}_{3}$-ApoA1 $(\beta=-0 \cdot 240 ; P=0.015)$ which is important in regulation of CETP activity (GuyardDangremont et al. 1994) and binding of CETP to HDL (MacPhearson et al. 1996).

Regression analysis showed that fasting CETP activity was associated with CETP mass; this has been shown in other studies (Clarke et al. 1995; Tato et al. 1995; Jones et al. 1996). CETP activity was determined using a new quick fluorimetric assay. Rapid analysis of samples was possible and use of radioactive substrates was excluded. When fluorimetric CETP activity assay was compared with an established CETP mass assay (Clarke et al. 1995), satisfactory correlation was achieved considering that plasma used for the CETP activity assay contained many of endogenous plasma proteins which inhibit or activate CETP activity unlike many previous methods of measuring CETP activity (Groener et al. 1986). This present study is one of the first to carry out a comparison of this new method for the measurement of CETP activity with an established method for the measurement of CETP mass.

Plasma non-esterified fatty acid concentration approached significance $(P=0.06)$ with CETP activity in this study as was also demonstrated by Largrost et al. (1995). Postprandial CETP activity at $6 \mathrm{~h}$ was associated with plasma cholesterol $(P=0.002)$, TAG-rich lipoprotein $(P=0.005)$ and mass $(P=$ $0.007)$ at $6 \mathrm{~h}$. This association demonstrates that CETP activity in postprandial lipaemia is perhaps influenced by the availability of cholesteryl ester and TAG. Lottenberg et al. (1996a), Lassel et al. (1998) and Mann (1991) have all demonstrated the importance of substrate availability in the regulation of CETP activity.

The frequency of the Taq 1B polymorphism of CETP was similar in our study group to that found in other studies (Bernard et al. 1998; Kuivenhoven et al. 1998). The relationship between the Taq 1B polymorphism and CETP mass, activity, and plasma lipids was investigated. The presence of the Taq 1B restriction site resulted in significantly higher $(P<0.002)$ fasting CETP and lower HDL-cholesterol concentrations (as has been demonstrated by Hannuksela et al. (1994), Kahri et al. (1998), and Kuivenhoven et al. (1998)) over those individuals who were homozygous for the absence of the polymorphism. We also found a significant effect $(P<0.05)$ of Taq 1B restriction fragment length polymorphism on $\mathrm{HDL}_{2}$-cholesterol concentrations (Freeman et al. 1993). The absence of Taq 1B restriction (B-B-) cutting site resulted in increased total HDL-phospholipid concentrations, a finding which has not been reported in any previous studies. These data seem to indicate that different alleles of CETP gene in a normolipidaemic population have an effect on CETP mass, HDL-cholesterol and -phospholipid concentrations. There is a lower concentration of CETP in those with B- B- allele. It could be hypothesised that there is less transfer of cholesteryl ester from HDL resulting in a greater concentration of cholesteryl ester being retained in the HDL fraction due to a lower concentration of CETP. There was a non-significant difference in CETP activity between the genotypes. These results conflict with previous studies (Freeman et al. 1993) which have suggested that association of HDL-cholesterol concentrations with Taq 1B was only identified in extreme situations, i.e. smokers, alcoholics, or $\alpha$-lipoproteinaemic but not in normolipidaemic subjects. From the data in this study it would seem that in the normal population depending on their Taq 1B genotype, there is either an increased risk or decreased risk of being susceptible to CHD as a result of the CETP genotype. There was no statically significant association between the presence and absence of Taq 1B polymorphism and $6 \mathrm{~h}$ CETP, HDL-cholesterol and -phospholipid concentrations. This lack of association may be as a result of increased lipid concentration during lipaemia masking the effect of Taq 1B polymorphism on plasma CETP and lipoprotein composition.

In summary, the findings of this present study were that there was a very significant increase in CETP mass, activity, plasma TAG, and $\mathrm{HDL}_{2}$ lipids in response to a test meal. CETP concentrations were associated with plasma cholesterol concentrations. Elevated CETP resulted in high LDL : HDL ratios demonstrating the pro-atherogenic effect of CETP in normolipidaemics. Increased neutral lipid exchange between lipoproteins as a result of CETP activity occurred during lipaemia suggesting the pro-atherogenic effects of CETP may be increased during postprandial lipaemia. Polymorphisms of CETP were also important in determining basal CETP and HDL-cholesterol and -phospholipid concentrations indicating that there is a genetic predisposition to either anti- or pro-atherogenic effects of CETP (elevated CETP concentrations resulting in low HDL-cholesterol). The data in this study implies that CETP may be pro-atherogenic at certain concentrations in 
normolipidaemic subjects and that this effect may be exacerbated during lipaemia.

\section{References}

Abbey M \& Nestel PJ (1994) Plasma cholesteryl ester transfer protein activity is increased when trans-elaidic acid is substituted for cis-oleic acid in the diet. Atherosclerosis 106, 99-107.

Bagdade JD, Ritter MC \& Subbaiah PV (1992) Accelerated cholesteryl ester transfer in plasma of patients with hypercholesterolemia. Journal of Clinical Investigation 87, 12591265.

Bernard S, Moulin P, Lagrost L, Picard S, Elchebly M, Ponsin G, Chapuis F \& Berthezene F (1998) Association between plasma high density lipoprotein cholesterol concentration and Taq 1B cholesteryl ester transfer protein gene polymorphisms in non insulin dependent diabetes mellitus. Journal of Lipid Research 39, 59-65.

de Bruin TWA, Brouwer CB, van Linde-Sibenius Trip M, Jansen H \& Erkelens DW (1993) Different postprandial metabolism of olive oil and soya bean oil: a possible mechanism of high density lipoprotein conserving effect of olive oil. American Journal of Clinical Nutrition 58, 477-483.

Castro GR \& Fielding CJ (1985) Effect of postprandial lipaemia on plasma cholesterol metabolism. Journal of Clinical Investigation 75, 874-882.

Clarke RW, Moberly JB \& Bamberger MJ (1995) Low level quantification of cholesteryl ester transfer protein in plasma subfractions and cell culture media by monoclonal antibody based immunoassay. Journal of Lipid Research 36, 876-889.

Freeman DJ, Griffin BA, Holmes P, Lindsay GM, Gaffney D, Packard CJ \& Shepard J (1993) Regulation of plasma HDL cholesterol and subfraction distribution by genetic and environmental factors. Associations between the Taq 1B RFLP in the CETP gene and smoking and obesity. Arteriosclerosis and Thrombosis 14, 336-344.

Freeman DJ, Packard CJ, Shepard J \& Gaffney D (1990) Polymorphisms in the gene coding for cholesteryl ester transfer protein are related to plasma high density lipoprotein cholesterol and transfer activity. Clinical Science 79, 575-581.

Fielding CJ \& Fielding PE (1995) Molecular physiology of reverse cholesterol transport. Journal of Lipid Research 36, 211-228.

Groener JE, van Ramhorst EM, Katan MB, Mensink RP \& van Tol A (1991) Diet induced alteration in the activity of plasma lipid transfer protein in normolipidemic human subjects. Atherosclerosis 87, 221-226.

Groener JEM, Pelton RW \& Kostner GM (1986) Improved estimation of cholesteryl ester transfer/exchange activity in serum or plasma. Clinical Chemistry 32, 283-286.

Guyard-Dangremont V, Lagrost L \& Gambert P (1994) Comparative effects of purified apolipoproteins A-1, A-II, and A-IV on cholesteryl ester transfer protein. Journal of Lipid Research $\mathbf{3 5}$, 982-991.

Inazo A, Brown ML, Hestler CB, Agellon LB, Koizumi J, Tulata K, Marumhama Y \& Tall AR (1990) Increased high density lipoprotein caused by common CETP gene mutation. New England Journal of Medicine 323, 1234-1238.

Inazu A, Koizumi J, Mabuchi H, Kajinami K \& Takeda R (1992) Enhanced cholesteryl ester transfer protein activities and abnormalities of high density lipoproteins in familial hypercholesterolemia. Hormone Metabolism Research 24, 284-288.

Hannuksela ML, Liinamaa MJ, Kesaniemi YA \& Slolainen MJ (1994) Relation of polymorphisms in the cholesterol ester transfer protein gene to transfer protein activity and plasma lipoprotein levels in alcohol drinkers. Atherosclerosis 110, 3444.
Jones RJ, Owens D, Brennan C, Collins PB, Johnson AH \& Tomkin GH (1996) Increased esterification of cholesterol and transfer of cholesterol ester to apo-B containing lipoproteins in type 2 diabetes: relationship to serum lipoproteins A-I and A-II. Atherosclerosis 119, 151-157.

Kahri J, Mikko S \& Taskinen MR (1994) Plasma cholesteryl ester transfer protein activity in non insulin dependent diabetic patients with and without coronary artery disease. Metabolism 43, 1498-1502.

Kahri J, Syvanne M \& Taskinen MR (1998) Plasma cholesteryl ester transfer protein activity in non-insulin-dependent diabetic patients with and without coronary artery disease. Metabolism 43, 1498-1502.

Karpe F, Steiner G, Olivercrona T, Carlson LA \& Hamsten A (1993) Metabolism of triglyceride rich lipoproteins during alimentary lipaemia. Journal of Clinical Investigation 91, $748-758$.

Koizumi J, Inazu A, Yagi K, Koizumi I, Kajinami K, Miyamoto S, Moulin P, Tall AR \& Mabuchi H (1991) Serum lipoprotein lipid concentration and composition in homozygous and hetrozygous patients with cholesteryl ester transfer protein deficiency. Atherosclerosis 90, 189-196.

Kuivenhoven JA, de Knijff P \& Boer JAM (1997) Heterogencity at the CETP gene locus: influence on plasma CETP concentrations and HDL cholesterol levels. Arteriosclerosis, Thrombosis and Vascular Biology 17, 560-568.

Kuivenhoven JA, Jukema JW, Zwinderman AZ, Knijff P, McPherson R, Bruschke AVG, Lie KI \& Kastelein JP (1998) The role of a common variant of the cholesterol ester transfer protein gene in the progression of coronary atherosclerosis. New England Journal of Medicine 338, 86-93.

Kondo IK, Berg D, Drayna D \& Lawn R (1989) DNA polymorphism at the locus for human cholesteryl ester transfer protein is associated with high density lipoprotein cholesterol and apolipoprotein levels. Clinical Genetics 35, 49-56.

Lagrost L, Florentin E, Athias A, Gandjini H, Lallemant C \& Gambert P (1995) Evidence for nonesterified fatty acids as modulators of neutral lipid transfers in normolipidemic plasma. Arteriosclerosis, Thrombosis and Vascular Biology 15, 13881396.

Lagrost L, Persegol C, Lallemant C \& Gambert P (1994) Influence of apolipoprotein composition of high density lipoprotein particles on cholesteryl ester transfer activity. Particles containing various proportions of apolipoproteins AI and AII. Journal of Biological Chemistry 269, 3189-3197.

Lassel TS, Guerin M, Auboiron S, Chapman MJ \& Guy-Gaurd B (1998) Preferential cholesteryl ester acceptor among triglyceride rich lipoproteins during alimentary lipemia in normolipidemic subjects. Arteriosclerosis, Thrombosis and Vascular Biology $\mathbf{1 8 ,}$ 65-74.

Lottenberg AM, Nunesm VS, Lottenberg SA, Shimabukuro AF, Carrilho AJ, Malagutti S, McPherson R \& Quintao EC (1996a) Plasma cholesteryl ester synthesis, cholesteryl ester transfer protein concentration and activity in hypercholesterolaemic women: effects of the degree of saturation of dietary fatty acids in the fasting and postprandial states. Atherosclerosis 126, 265-275.

Lottenberg SA, Lottenberg AM, Nunes VS, MacPherson R \& Quintao EC (1996b) Plasma cholesteryl ester transfer protein concentration, high density lipoprotein cholesterol esterification and transfer rates to lighter density lipoproteins in the fasting state and after a test meal are similar in type II diabetics and normal controls. Atherosclerosis 127, 81-90.

Mann CJ (1991) Mechanism of plasma cholesteryl transfer in hypertriglyceridaemia. Journal of Clinical Investigation $\mathbf{6}$, 2059-2066.

MacPherson R, Agnani G, Lau P, Fruchart JC, Edgar AD \& Marcel 
YL (1996) Role of Lp A-1 and Lp A-1/A-II in cholesteryl ester transfer protein mediated neutral lipid transfer studies in normal subjects and in hypertriglyceridemic patients before and after fenofibrate therapy. Arteriosclerosis, Thrombosis and Vascular Biology 16, 1340-1346.

Patsch JR, Prasad S, Gotto AM \& Olivecrona GB (1984) Postprandial lipaemia; A key for the conversion of high density lipoprotein $_{2}$ into high density lipoprotein 3 by hepatic lipase. Journal of Clinical Investigation 74, 2017-2023.

Patsch JR, Prasad S, Gotto AM \& Patsch W (1987) High density lipoprotein-2. Relationship of the plasma levels of this lipoprotein species to its composition, to the magnitude of postprandial lipaemia, and to the activities of lipoprotein lipase and hepatic lipase. Journal of Clinical Investigation 80, 341347.

Quinet EM (1990) Atherogenic diets increases cholesteryl ester transfer protein messenger RNA levels in rabbit. Journal of Clinical Investigation 85, 357-363.

Savolainen MJ, Hannuksela M, Seppanen S, Kervinen K \&
Kesaniemi YA (1990) Increased high density lipoprotein in alcoholics is related to low cholesteryl ester transfer protein activity. European Journal of Clinical Investigation 20, 593-599.

Skinner ER (1994) High density lipoproteins. Current Opinions in Lipidology 5, 241-247.

Tall AR (1986) Plasma lipid transfer proteins. Journal of Lipid Research 27, 361-368

Tall AR (1993) Plasma cholesteryl ester transfer protein. Journal of Lipid Research 34, 1255-1274.

Tato F, Vega GL \& Grundy SM (1997) Determinants of plasma HDL-cholesterol in hypertriglyceridemic patients. Role of cholesterol ester transfer protein and lecithin cholesteryl acyl transferase. Arteriosclerosis, Thrombosis and Vascular Biology 17, 56-63.

Tato F, Vega GL, Tall AR \& Grundy SM (1995) Relation between cholesterol ester transfer protein activities and lipoprotein cholesterol in patients with hypercholesterolemia and combined hyperlipidaemia. Arteriosclerosis, Thrombosis and Vascular Biology 15, 112-120. 